Federal Reserve Bank of Minneapolis

Research Department Staff Report 228

Revised March 2003

\title{
Hot Money*
}

\author{
V. V. Chari
}

Federal Reserve Bank of Minneapolis

and University of Minnesota

Patrick J. Kehoe

Federal Reserve Bank of Minneapolis, University of Minnesota, and National Bureau of Economic Research

\begin{abstract}
Recent empirical work on financial crises documents that crises tend to occur when macroeconomic fundamentals are weak, but that even after conditioning on an exhaustive list of fundamentals, a sizable random component to crises and associated capital flows remains. We develop a model of herd behavior consistent with these observations. Informational frictions together with standard debt default problems lead to volatile capital flows resembling hot money and financial crises. We show that repaying debt during difficult times identifies a government as financially resilient, enhances its reputation and stabilizes capital flows. Bailing out governments deprives resilient countries of this opportunity.
\end{abstract}

*Both authors thank the NSF for research support. The views expressed herein are those of the authors and not necessarily those of the Federal Reserve Bank of Minneapolis or the Federal Reserve System. 


\section{Introduction}

Financial booms and crises in emerging economies are tightly linked to capital flows: sometimes large amounts of capital flow into a country, leading to a financial boom, and sometimes large amounts flow out, leading to a crisis. Two common features of financial crises in emerging economies are key to understanding this phenomenon: crises tend to occur in countries in which macroeconomic fundamentals are weak, and even after the historical crises data are conditioned on an extensive list of macroeconomic fundamentals, a sizable nonfundamental, or random, component to the crises remains. (See Kaminsky 1999 and others.)

That random component of international capital flows is the subject of this study. In discussing financial crises, Calvo and Mendoza (1995) argue that a country's " 'fall from grace' in world capital markets . . . may be driven by herding behavior not necessarily linked to fundamentals." We think the herding story is a promising explanation of the random component of capital flows that drive financial crises.

This paper formalizes that herding story. In our model, when macroeconomic fundamentals are weak, capital tends to flow out. However, weak fundamentals alone do not account for all capital flows; herd behavior drives some of them. Investors are uncertain about whether countries will repay their debt in difficult times. Informational frictions lead investors to stampede toward or away from a country when the investors have only bits of information. Hence, capital flows in our model have the characteristics of hot money.

In our model, we associate financial crises with sudden outflows of capital, as does Calvo (1998). Our model builds on the work of Banerjee (1992) and Bikhchandani, Hirshleifer, and Welch (1992), who develop stylized models of herdlike behavior in which investors must move in a prespecified order. One contribution of our study is that we endogenize the timing 
of investors' moves. In our model, investors can invest at any time. They must decide whether to make a risky investment in the emerging economy or a safe investment in the rest of the world. Information about the riskiness of the investment arrives over time. Specifically, in each period, a signal about the return on the risky investment arrives to the economy and is privately observed by one of the investors. Investors observe the aggregate amount of investment in each period and optimally decide whether to invest or wait for more information. Waiting is costly because of discounting.

Our model generates capital flows which are sensitively dependent on the exact pattern of signals. If the signals lead investors to be sufficiently optimistic, then investors choose to forgo the opportunity to acquire information, and they all immediately invest in the emerging economy. If investors become sufficiently pessimistic, then they all invest in the rest of the world, and capital flows out of the emerging economy. We call such hot money-like patterns of capital flows herds.

The source of the investment risk in the emerging economy is the possibility of expropriation or default by the country's government. Our model has two types of government: a competent, or resilient, type, which can efficiently deal with difficult times, and an incompetent type, which cannot. In the model's equilibrium, the competent type never defaults on its debt while the incompetent type does default, but only during difficult times. This feature captures the idea that in normal times, different types of government may perform equally well, but difficult times reveal their true nature: some governments crack under pressure while others do not.

Our model generates the two key features of financial crises documented by Kaminsky (1999). Fundamentals play an important role in generating crises: capital outflows are more 
likely when fundamentals are weak, and capital inflows are more likely when fundamentals are strong. But even when fundamentals are weak, crises cannot be accounted for solely by macroeconomic fundamentals. We show that capital flows in or out depending on the specific pattern of the realization of signals across investors.

Our model provides two additional insights. One is that by repaying debt during difficult times, governments pass a test of fire and thus enhance their reputation and capital flows. Both of those are hurt if governments fail that test. Difficult times are crucial for identifying financially resilient governments since no such test can occur in normal times.

The other insight from our model is that bailing out governments in difficult times involves a cost not before appreciated: signal-jamming. Bailouts by outside agents jam signals to investors about the governments' financial resilience and thus deprive resilient governments of the opportunity to enhance their reputations. If unanticipated, bailouts don't involve moral hazard, but they do involve signal-jamming.

We interpret our model as suggesting that middle-income countries are most likely to experience herd behavior. The richest countries have developed institutions to handle crises well. Hence, investors do not worry about default in these countries, and a steady stream of capital flows to them. Similarly, investors have no confidence in the poorest countries' ability to handle crises, and essentially no private capital goes to them. Uncertainty about the resilience of governments is likely to be the highest among the middle-income countries, and our model suggests that herd behavior will be most common among them.

Our model has many antecedents. Our modeling of the investors builds on elements of the literature on herd behavior (for example, Banerjee 1992; Bikhchandani, Hirshleifer, and Welch 1992; Caplin and Leahy 1994; and Chamley and Gale 1994). Our modeling of the 
government builds on elements of the debt default literature with signaling. (See the Eaton and Fernandez 1995 survey.)

Our work is also complementary to models of financial crises driven by sunspots. (See, for example, Sachs, Tornell, and Velasco 1996; Calvo 1998; Cole and Kehoe 2000; and Chang and Velasco 2001.) The sunspot equilibria in these models arise from coordination problems. For example, in Cole and Kehoe (2000), lending is optimal for an individual lender if and only if other lenders are lending. Morris and Shin (2001) critique sunspot equilibria arising from coordination problems. They show that in a large class of coordination games, if agents have an arbitrarily small amount of idiosyncratic private information about fundamentals, there can be no (nontrivial) sunspot equilibria. Our model is not driven by coordination problems; nor are our equilibria sunspot equilibria. Thus, our model is not subject to the Morris and Shin (2001) critique. Nonetheless, one interpretation of our herding model is that it provides a detailed microeconomic story to explain sunspots. In particular, changes in the order that signals are observed can change outcomes dramatically, in much the same way that sunspots can change outcomes in models with coordination problems.

\section{Macroeconomic Fundamentals and Financial Crises}

The early literature on financial crises, following Krugman (1979), points to the macroeconomic fundamentals that are likely to play a key role. In this fundamentalist literature, crises can be completely accounted for by macroeconomic fundamentals. (For some recent work along fundamentalist lines, see Atkeson and Ríos-Rull 1996 and Burnside, Eichenbaum, and Rebelo 2000.)

The empirical work on financial crises raises two challenges to the fundamentalist view. 
This work shows that fundamentals can account for only a modest fraction of observed crises. And it shows that even after the historical crisis data are conditioned on an extensive list of macroeconomic fundamentals, a sizable random component remains. (See the references in Goldstein, Kaminsky, and Reinhart 2000.)

For example, Kaminsky (1999) develops what seems to be an exhaustive list of indicators of financial crises during 1970-95 for 20 countries, encompassing 102 financial crises. The indicators are those suggested by the fundamentalist literature, movements in things like a country's output, real interest rates, stock prices, bank deposits, exports, imports, terms of trade, real exchange rate, foreign debt, and M1 money balances. She divides the sample period into crisis times, defined as the 24 months immediately before an actual financial crisis, and tranquil times, defined as all other times. Using the crisis indicators, she constructs the probability that a financial crisis will occur in the next 24 months. She finds that, on average, the probability of a currency crisis occurring is .39 in crisis times and .19 in tranquil times. That is, on average, her fundamentals model mistakenly predicts no crisis 61 percent of the time in crisis times and mistakenly predicts a crisis 19 percent of the time in tranquil times.

As an illustration, consider Figure 1, which displays Kaminsky's (1999) probability that a currency crisis will occur in the next 24 months in Malaysia. Crises actually occurred there in July 1975 and July 1997. The shaded areas of the graph are the crisis times. Notice that before the 1975 crisis, the model predicts a relatively low probability of a crisis, but one occurred. In the mid-1980s, the model predicts a high probability of a crisis, but none occurred. In sum, while the data show that fundamentals play an important role in financial crises, a very sizable amount of randomness clearly remains. 


\section{Investor Behavior}

We build a model which is consistent with those facts. We begin, in this section, by describing investor behavior during one period of an infinite-horizon dynamic economy, with the risk structure of investments given exogenously. In the next section, we will build a maximizing model of government behavior and provide sufficient conditions for the default decisions of this government to generate the risk structure that we assume here.

\section{A. Herds with Endogenous Timing}

Consider one period of a model of a small open economy with domestic and foreign investors. The single period has $V+1$ stages, denoted $t=0, \ldots, V$.

At each stage, investors must decide whether to make a risky investment in the emerging economy or a safe investment in the rest of the world. Information about the returns to the risky investment arrives over time in the sense that at each stage a signal about the return of the risky investment arrives to the economy and is privately observed by one of the investors. Investors observe the aggregate amount of investment at each stage and optimally decide whether to invest or to wait for more information. Waiting has both benefits and costs. The benefit is the possibility of inferring other investors' signals from their decisions. The cost arises from discounting.

The economy has $N$ one-period-lived risk-neutral investors, a fraction $\lambda$ of whom are domestic and a fraction $1-\lambda$ of whom are foreign. (We include domestic investors so that a failure to make domestic investments corresponds to capital flight.) Each investor has 1 unit of resources to invest. Investors have a choice of two types of investment: a safe foreign investment with a gross return that is normalized to 1 and a risky domestic investment. The 
payoff on the risky investment depends on the state of the economy, denoted $g \in\{G, B\}$, where $G$ indicates a good state and $B$, a bad state. The state is realized at stage 0 , but is not known to investors until stage $V$. The distribution is common knowledge among investors. The common prior probability of the good state at stage 0 is $\mu_{G}$.

Each investor starts at stage 0 with 1 unit invested in the safe investment and at each stage $t$ chooses whether to switch from the safe investment to the risky investment. Once investors have switched their unit, they must leave it there until stage $V$. The risky investment compounds at a gross rate $R>0$. If the state is good, then the investor gets the compounded amount at state $V$. If the state is bad, then the investor gets the compounded amount with probability $\pi_{0}$ and gets nothing with probability $1-\pi_{0}$. (In the next section, $\pi_{0}$ will turn out to be the probability that the government is competent.) Hence, an investor who switches at stage $t$ gets a total expected return of

$$
e^{R(V-t)}\left\{\operatorname{Pr}_{t}(\text { state is } G)+\pi_{0} \operatorname{Pr}_{t}(\text { state is } B)\right\}
$$

where $\operatorname{Pr}_{t}$ (state is $G$ ) is the conditional probability that the investor assigns to the state being $G$, with similar notation for the state being $B$. An investor who never switches gets a total return of 1 . Notice that after investors switch to the risky investment, they take no more actions. Hence, we do not need to define payoffs or strategies for such investors.

Investors receive signals $s \in\{G, B\}$ about the state as follows. At each stage $t=$ $0, \ldots, S$, which satisfies $S<V$, one signal arrives to the economy and is randomly distributed to one and only one investor among the set of investors who have not already received a 
signal. ${ }^{1}$ The signals are informative and symmetric in the sense that

$$
\operatorname{Pr}(s=G \mid g=G)=\operatorname{Pr}(s=B \mid g=B)=\alpha>1 / 2 .
$$

The only publicly observable events are the number of investments at each stage. Let $n_{t}$ denote the number of new investments at $t$. The public history $h_{t}=\left(n_{0}, n_{1}, \ldots, n_{t-1}\right)$ records the aggregate number of positive investments at each stage up through the beginning of stage $t$. Investors also record the signal they receive, if any, and the stage at which they receive it. The history of an investor $i$ at $t$ who receives a signal at stage $r$ is $h_{i t}=\left(h_{t}, s_{r}, r\right)$, and $\left(h_{t}, \emptyset, \emptyset\right)$ denotes the history of an investor who has not received a signal.

Notice that at each stage $t$, given their histories, investors can be described as belonging to one of several groups. Any investor who has already invested is inactive. The active investors are of three types: a newly informed investor who has received the signal at the beginning of stage $t$, previously informed investors who have received a signal at some stage $r$ before $t$, and uninformed investors who have not yet received a signal.

An investor's strategy and beliefs (or priors) are sequences of functions $x_{t}\left(h_{i t}\right)$ and $p_{t}\left(h_{i t}\right)$ that map the investor's histories into actions and priors over the state. The payoffs are defined as follows. Let $V_{t}\left(h_{i t}\right)$ denote the payoff for an investor who switches from the safe to the risky investment at $t$ conditional on the history $h_{i t}$. Then

$$
V_{t}\left(h_{i t}\right)=e^{R(V-t)} q_{t}\left(h_{i t}\right)
$$

where for simplicity we let $q_{t}\left(h_{i t}\right)=p_{t}\left(h_{i t}\right)+\pi_{0}\left[1-p_{t}\left(h_{i t}\right)\right]$ is the probability of receiving

\footnotetext{
${ }^{1}$ Hence, $S$ investors are randomly drawn without replacement from the pool of $N$ investors and assigned a number designating the stage at which each will receive a signal. The names of the investors and the stages when they will receive the signals are not observed, but the process for assigning names and stages is common knowledge.
} 
the compounded return on the risky asset conditional on the history. Let $W_{t}\left(h_{i t}\right)$ denote the payoff for an investor who waits at stage $t$. The payoff to waiting is given by

$$
W_{t}\left(h_{i t}\right)=\sum_{h_{i t+1}} \mu_{t}\left(h_{i t+1} \mid h_{i t}\right) \max \left\{V_{t+1}\left(h_{i t+1}\right), W_{t+1}\left(h_{i t+1}\right)\right\}
$$

where $\mu_{t}\left(h_{i t+1} \mid h_{i t}\right)$ is the conditional distribution over investor $i$ 's histories at $t+1$ given this investor's history at $t$. Notice that the conditional distribution $\mu_{t}\left(h_{i t+1} \mid h_{i t}\right)$ is induced from the strategies and the structure of exogenous uncertainty of the economy in the obvious way. Notice also that we have imposed symmetry by supposing that all investors who have the same histories have the same beliefs and take the same actions.

Here a perfect Bayesian equilibrium is a set of strategies $x_{t}\left(h_{i t}\right)$, a set of conditional distributions $\mu_{t}\left(h_{i t+1} \mid h_{i t}\right)$, and a set of beliefs $p_{t}\left(h_{i t}\right)$ such that $(i)$ for every history $h_{i t}, x_{t}\left(h_{i t}\right)$ is optimal for all active investors, and $(i i)$ the conditional distributions $\mu_{i t}\left(h_{i t+1} \mid h_{i t}\right)$ and the beliefs $p_{i t}\left(h_{i t}\right)$ are consistent with Bayes' rule wherever possible, but are arbitrary otherwise. To simplify the construction of an equilibrium, we let $P_{G}(p)$ and $P_{B}(p)$ be the posterior probabilities associated with a good signal and a bad signal, respectively, when the prior is given by $p$. Thus, from Bayes' rule we have

$$
\begin{aligned}
& P_{G}(p)=\frac{p \alpha}{p \alpha+(1-p)(1-\alpha)} \\
& P_{B}(p)=\frac{p(1-\alpha)}{p(1-\alpha)+(1-p) \alpha}
\end{aligned}
$$

where $\alpha$ is defined in (2). Let $P(0)=\mu_{G}, P(1)=P_{G}(P(0)), P(2)=P_{G}(P(1))$, and so on, and let $P(-1)=P_{B}(P(0)), P(-2)=P_{B}(P(-1))$, and so on. Thus, $P(k)$ for $k>0$ is the prior probability that the state is good if $k$ good signals have been received, and $P(k)$ for 
$k<0$ is the prior probability that the state is good if $k$ bad signals have been received. Notice from the symmetry in (2) that

$$
P_{G}\left(P_{B}(p)\right)=P_{B}\left(P_{G}(p)\right)=p .
$$

It follows from (5) that the effect on the prior of a given set of signals is summarized by the number of good signals minus the number of bad signals in the set. For example, receiving two good signals and one bad signal yields the same prior as receiving one good signal.

Let $Q(k)=P(k)+\pi_{0}[1-P(k)]$. Notice that $Q(k)$ is an investor's belief about the probability of a risky investment paying off a positive amount, since investors believe the state is good with probability $P(k)$.

Now we consider the region of the parameter space that satisfies these assumptions:

$$
\begin{aligned}
& 1<e^{R(V-S)} Q(0) \\
& 1>e^{R V} Q(-1) \\
& e^{R V} Q(0)<\nu_{G}(P(0)) e^{R(V-1)} Q(1)+\nu_{B}(P(0)) .
\end{aligned}
$$

Here $\nu_{G}(p)=P(s=G \mid p)=p \alpha+(1-p)(1-\alpha)$ and $\nu_{B}(p)=P(s=B \mid p)=p(1-\alpha)+(1-p) \alpha$ denote the probabilities that the signal is good and bad, respectively, given a prior of $p$.

Note that because $R$ is positive, these assumptions imply the following. Assumption (6) implies that at any stage $t$, if the investor is forced to choose between the two options of investing in the risky investment given belief $Q(0)$ or never investing in the risky investment, investing is better. Assumption (7) implies that at any stage $t$, if the investor is forced to choose between the two options of investing in the risky investment given belief $Q(-1)$ or 
never investing in the risky investment, not investing is better. We can think of assumptions (6) and (7) as conditions on the prior $P(0)$.

Assumption (8) implies that

$$
e^{R(V-t)} Q(0)<\nu_{G}(P(0)) e^{R(V-t-1)} Q(1)+\nu_{B}(P(0)) .
$$

To gain some intuition for (9), consider an alternative economy in which an investor at stage $t$ expects to receive a signal at stage $t+1$ with probability 1 . Suppose also that the investor is restricted to making an investment decision in either stage $t$ or stage $t+1$. Inequality (9) implies that in this alternative economy, investing with beliefs $Q(0)$ is dominated by waiting until stage $t+1$ and investing if and only if a good signal is realized. To understand the role of (8) in our model, note that waiting and receiving information is beneficial because investors have the option of not investing if the signals are sufficiently bad. We call this benefit the no investment option value. The cost of waiting comes from a kind of discounting, in that investors forgo the flow return from investing. Assumption (8) requires that the no investment option value be large relative to discounting. We interpret (8) as an assumption that investors discount the future little.

Now we will informally describe the strategies of the various types of investors. At all stages before $S$, the strategy of the uninformed and previously informed investors is to invest if and only if the prior is at least $P(1)$. The strategy for newly informed investors is to invest if and only if the prior is at least $P(0)$. From these strategies, it is easy to construct how beliefs evolve.

These strategies lead to the following equilibrium outcomes. At the beginning of stage 0 , one investor receives a signal and is the newly informed investor. That investor invests if 
the signal is good but otherwise does not. All uninformed investors wait.

The decisions at stage 1 depend on the history from stage 0 . If investment was positive at stage 0 , then the uninformed investors infer that the signal at stage 0 was good, their priors rise to $P(1)$, and they all invest, while the newly informed investor at stage 1 invests regardless of the signal that investor actually received. We say that this history starts a stampede of investment, in that all investors invest regardless of their signals. If investment was zero at stage 0 , then the uninformed investors infer that the signal at stage 0 was bad, their priors fall to $P(-1)$, and they all wait. The newly informed investor at stage 1 invests if the signal received is good, but waits otherwise.

At the beginning of stage 2 , if investment has been zero at both stages 0 and 1 , then uninformed investors' priors fall to $P(-2)$, and no investor invests at stage 2 or at any subsequent stage. We will say that this history starts a stampede of no investment, in that all investors do not invest regardless of their signals. If there has been no investment at stage 0 but an investment at stage 1 , then both the uninformed investors and the previously informed investor have a prior of $P(0)$, they wait, and the newly informed investor invests if and only if the signal is good.

More generally, histories of the form $(1),(0,1,1), \ldots,(0,1,0,1, \ldots, 0,1,1)$ start stampedes of investment. Histories of the form $(0,0),(0,1,0,0), \ldots,(0,1,0,1, \ldots, 0,1,0,0)$ start stampedes of no investment.

More formally, we proceed as follows. The strategy for uninformed and previously informed investors is

$$
x_{t}\left(h_{i t}\right)=\left\{\begin{array}{c}
1 \text { if } p_{t}\left(h_{i t}\right) \geq P(1) \\
0 \text { otherwise }
\end{array}\right\}
$$


for $t \leq S-1$ and $x_{S}\left(h_{i S}\right)=1$ if and only if $p_{S}\left(h_{i S}\right) \geq P(0)$. The strategy for newly informed investors is

$$
x_{t}\left(h_{i t}\right)=\left\{\begin{array}{c}
1 \text { if } p_{t}\left(h_{i t}\right) \geq P(0) \\
0 \text { otherwise }
\end{array}\right\}
$$

for $t \leq S$. Note that $p(1)$ is a cutoff level for investment by the uninformed and previously informed investors and $P(0)$ is that level for newly informed investors. Note, too, that in order to invest before $S$, the uninformed and previously informed investors need to be more optimistic than newly informed investors.

The beliefs of uninformed investors with history $h_{i t}=\left(h_{t}, \emptyset, \emptyset\right)$ are recursively defined. Given $p_{t-1}\left(h_{i t-1}\right)$ and a total investment of $n_{t-1}$ at stage $t-1$, the beliefs at $t$ are given as follows. For $p_{t-1}\left(h_{i t-1}\right)$ equal to either $P(-1)$ or $P(0)$,

$$
p_{t}\left(h_{i t}\right)=\left\{\begin{array}{c}
P_{B}\left(p_{t-1}\left(h_{i t-1}\right)\right) \text { if } n_{t-1}=0 \\
P_{G}\left(p_{t-1}\left(h_{i t-1}\right)\right) \text { if } n_{t-1}=1 \\
P(2) \text { if } n_{t-1} \geq 2
\end{array}\right\}
$$

where $p_{0}\left(h_{i 0}\right)=\mu_{G}$. For $p_{t-1}\left(h_{i t-1}\right)$ either greater than or equal to $P(1)$ or less than or equal to $P(-2), p_{t}\left(h_{i t}\right)=p_{t-1}\left(h_{i t-1}\right)$.

The beliefs of the newly informed investors with history $h_{i t}=\left(h_{t}, s, t\right)$ are simply those of the uninformed investors, updated by the newly informed investors' signal: $p_{t}\left(h_{t}, s, t\right)=$ $P_{s}\left(p_{t}\left(h_{t}, \emptyset, \emptyset\right)\right)$ for $s=G, B$.

The beliefs of the previously informed investor at $t$ who received a signal at $t-1$ with history $h_{i t}=\left(h_{t}, s, t-1\right)$ are defined as follows. If no other investor invested at $t-1$, then this investor's beliefs are the same as they were at stage $t-1: p_{t}\left(h_{t}, s, t\right)=P_{s}\left(p_{t-1}\left(h_{t-1}, \emptyset, \emptyset\right)\right)$ for $s=G, B$. If some other investor invested at $t-1$, then $p_{t}\left(h_{t}, s, t\right)=P(2)$. The beliefs 
of previously informed investors who received their signals before stage $t-1$ are recursively defined as those of the uninformed investors, except that the recursion now starts at $r$, with the beliefs of the newly informed investor at $r, p_{r}\left(h_{i r}, s, r\right)$.

Built into these beliefs is the idea that investors look at previous investors' actions and try to infer the signals they received. On the equilibrium path and for undetectable deviations from an investor's strategy, the uninformed investors infer the following. If they see one unit of investment at $t$ and the strategies specify that a newly informed investor receiving a good signal should invest, while a newly informed investor receiving a bad signal should not invest, then the uninformed investors infer that the newly informed investor received a positive signal. The uninformed investors update beliefs in a similar way when they see no investment at $t$. Notice that when the newly informed investors act differently than their strategies specify, these deviations cannot be detected by uninformed investors, so that uninformed investors' beliefs are updated as if the informed investors had not deviated.

On the equilibrium path and for undetectable deviations, the newly informed investors simply update the beliefs of the uninformed investors with their private signals. The previously informed investor who was newly informed at $t-1$ simply updates the beliefs of the newly informed investor at $t-1$ appropriately. The previously informed investor who was newly informed at $r<t-1$ simply updates the beliefs of the previously informed investor at $t-1$ appropriately.

For detectable deviations, investors infer the following. If an uninformed investor sees more than one unit of investment, beliefs are updated to an optimistic level, $P(2)$. If an uninformed investor sees other deviations, beliefs are left unchanged. Previously informed investors behave similarly. A newly informed investor at $t$ who is active at $t+1$ and sees 
investments by others also updates beliefs to the optimistic level $P(2)$.

These strategies and beliefs induce the conditional distributions $\mu_{t}\left(h_{i t+1} \mid h_{i t}\right)$ in the obvious way. We will show that these strategies and beliefs are an equilibrium. An important feature of the strategies is that the cutoff level for investment is higher for the uninformed investors than for the newly informed investors. To understand why this is necessary, suppose first that both types of investors invest if their beliefs are greater than or equal to $P(0)$. To see why this cannot be an equilibrium, consider a deviation to waiting by an uninformed investor at $t=0$ with beliefs $P(0)$. Since the newly informed investor invests if and only if the investor's signal is good, the deviating investor learns the value of the signal. By (8), this deviation increases payoffs.

Suppose next that the cutoff level for both types of investors is $P(1)$. Suppose the first signal is $B$. Then the newly informed at stage 0 does not invest, and the other investors infer that the newly informed got a bad signal, and their priors are $P(-1)$. The newly informed investor at stage 1 is supposed to wait regardless of the signal. The prior of the uninformed investor stays at $P(-1)$, and thus, all newly informed investors at all future stages also wait. After a history of signals $B, G$, the newly informed investor at stage 1 has a prior of $P(0)$. A deviation to investing, by (6), raises the payoffs.

These arguments help explain why the cutoff levels of the informed and uninformed investors must be different. We now show that when these cutoff levels have the form in (10) and (11), the strategies and beliefs are an equilibrium.

Proposition 1. Under assumptions (6)-(8), the strategies and beliefs in (10) and (11) constitute a perfect Bayesian equilibrium. 
Proof. By construction, the beliefs in (12) satisfy Bayes' rule. We repeatedly use the observation that by construction, for any history $h_{i t}, p_{t}\left(h_{i t}\right)=P(k)$ for some integer $k$.

First consider optimality for histories with no detectable deviations. Consider the strategies of the uninformed investors with different histories $h_{i t}$. If $p_{t}\left(h_{i t}\right) \leq P(-1)$, then by (7), waiting is optimal. If $p_{t}\left(h_{i t}\right)=P(0)$, then by (8), waiting is optimal.

More interesting is a history with $p_{t}\left(h_{i t}\right)=P(1)$. Under the equilibrium, the uninformed investor invests and receives $e^{R(V-t)} Q(1)$. Suppose the investor instead deviates and waits. If, for all future histories, the investor ends up investing, then waiting merely reduces the length of time in the high return investment, and the investor loses $e^{R}$ at each stage. Thus, the only way that this deviation can be profitable is if there are some future histories in which this investor never invests. Consider the most pessimistic information the investor could receive. Recall that for such a history, all other active investors invest at $t$. Thus by waiting, the uninformed investor receives no new information from others. By waiting, the uninformed investor could receive a signal in the future. But even if the future signal is $s=B$, this investor's belief will be $P(0)$, and by (6) the investor will invest. Thus, even under the most pessimistic information, investing is optimal; so waiting is not profitable. Finally, for histories with $p_{t}\left(h_{i t}\right) \geq P(1)$, investing is also clearly optimal.

Consider next the strategies of the newly informed investors for some history $h_{i t}$. If $p_{t}\left(h_{i t}\right) \leq P(-1)$, then $(7)$ implies that waiting is optimal. If $p_{t}\left(h_{i t}\right) \geq P(2)$, then along the equilibrium, uninformed investors have already invested, there is no potential information to learn, and by (6), investing is optimal.

The interesting histories are those in which the uninformed investors' beliefs are $P(0)$ or $P(-1)$ and the newly informed investor has just received a good signal, so that the investor's 
beliefs are $P(1)$ or $P(0)$. The strategy for the newly informed investor specifies investing. Suppose this investor instead deviates and waits, presumably to garner information about the signals of subsequent informed investors. If for all future histories the investor ends up investing, then for this investor, too, waiting merely reduces the length of time in the high return investment. Thus, again, the only way that this deviation can be profitable is if there are some future histories in which this investor never invests. After such a deviation, the beliefs of the newly informed investor are 2 units higher than those of the uninformed investors in that the newly informed investor has beliefs $P(k+2)$ when the beliefs of the uninformed investors are $P(k)$. The reason is that the newly informed investor's private signal raised that investor's beliefs by 1 unit, and the deviation by the newly informed investor did not affect that investor's own beliefs while it lowered the uninformed investors' beliefs by 1 unit.

Consider a history $h_{i t}$ in which the uninformed investors' beliefs are $P(-1)$ and the newly informed investor receives a good signal and, hence, has beliefs $P(0)$. If the newly informed investor deviates and waits, then this deviation triggers a stampede with no investment. To see this, note that the deviation causes the uninformed investors' beliefs to be $P(-2)$ permanently. Given these beliefs, uninformed investors never invest. Future newly informed investors update their beliefs to at most $P(-1)$ and do not invest either. Thus, this deviation brings the investor no new information. The beliefs of the deviating investor remain at $P(0)$. Assumption (6) then implies that given these beliefs, the optimal action for the newly informed investor is to invest at stage $t$.

Next, consider a history $h_{i t}$ in which the uninformed investors' beliefs are $P(0)$ and, again, the newly informed investor receives a good signal, so now has beliefs $P(1)$. Suppose the newly informed investor deviates and waits. Then, at the next stage, the uninformed 
investor's beliefs fall to $P(-1)$ while the informed investor's beliefs stay at $P(1)$. Recall that the deviating investor's prior is always 2 units higher than the prior of the uninformed investors and that a stampede of no investment starts when the priors of the uninformed investors reach $P(-2)$. Thus, the most pessimistic information that the deviating investor can get leads to a prior of $P(0)$. At this prior, investing is optimal; thus, the deviation is not profitable.

Finally, after histories with detectable deviations and at stage $S$, it is easy to check that no investor has an incentive to deviate. Q.E.D.

Next we show that within a certain class, the equilibrium we have constructed is unique. We say that a collection of strategies and beliefs is a symmetric, stationary equilibrium if it is a perfect Bayesian equilibrium and the strategies have the cutoff rule form. Namely, there are sets of integers $I$ and $I^{\prime}$ such that for $t \leq S-1$ the strategies of the uninformed and previously informed investors are of the form $x_{t}\left(h_{i t}\right)=1$ if and only if $p_{t}\left(h_{i t}\right) \in I$, while the strategy for newly informed investors is of the form $x_{t}\left(h_{i t}\right)=1$ if and only if $p_{t}\left(h_{i t}\right) \in I^{\prime}$. (Notice that we allow the strategies at $S$ to differ from those at $t \leq S-1$.) We let the beliefs be defined as before.

Proposition 2. The strategies and beliefs just described are the unique symmetric, stationary equilibrium.

Proof. Consider the investors' problem at stage S. Assumptions (6) and (7) imply that all investors invest if and only if their beliefs are greater than or equal to $P(0)$. Consider next the investors' problem at stage $S-1$. The newly informed investor can learn nothing by waiting, so invests if and only if the investor's beliefs are greater than or equal to $P(0)$. Thus, 
the set $I^{\prime}$ is the set of integers with $k \geq 0$. By waiting, an uninformed investor who enters this stage with beliefs $P(0)$ learns the signal of the newly informed investor. And by (8), waiting is optimal. An uninformed investor who enters this stage with beliefs greater than or equal to $P(1)$ will invest at stage $S$ regardless of the newly informed investor's action. Hence, for that investor, waiting only postpones investment, and investing immediately is optimal. Thus, the set $I$ is the set of integers with $k \geq 1$. Q.E.D.

\section{B. Public vs. Private Signals}

Next we demonstrate that there are two senses in which the capital flows described above have a primary characteristic of hot money; they are excessively volatile. First, we show that the stampedes in the private signal economy are, in a sense, inefficient relative to an economy with public signals. Second, we show that the variance of capital flows conditional on fundamentals is larger in the private signal economy than in the public signal economy.

The relevant benchmark here is a public signal economy which captures the informational lags built into the private signal economy. Consider an economy with informational lags in which the uninformed investors learn the realization of the stage $t$ signal after they have made their stage $t$ investment decisions. Here, as before, newly informed investors observe the realization of the stage $t$ signal before making their stage $t$ investment decisions. Thus, at $t$ the relevant history of investors is the history of past investments $\left(m_{0}, m_{1}, \ldots, m_{t-1}\right)$ together with the history of the signals. For the newly informed investor, the history of signals is $s^{t}=\left(s_{0}, s_{1}, \ldots, s_{t}\right)$, while that for all other investors is $s^{t-1}$. An equilibrium is defined as before. For any equilibrium, the outcome path can be defined recursively from the strategies and depends only on the history of signals. The equilibrium strategies induce outcomes at 
each stage. For the public signal economy, let $m_{t}\left(s^{t}\right)$ denote the aggregate number of positive investments at $t$ for history $s^{t}$. Similarly, in the private signal economy, let $n_{t}\left(s^{t}\right)$ denote the aggregate number of positive investments along the equilibrium path at $t$ for history $s^{t}$.

We say that the private signal economy has a herd if for some realization of signals $s^{t}$, the economy has a stampede, in the sense that all investors take the same action from then on, regardless of their signals, and the stampede is inefficient in the sense that the economy's aggregate investments differ from those of the public signal economy. Formally, the private signal economy has a herd at $s^{t}$ if $(i)$ for all future histories $s^{r}$ containing $s^{t}, n_{r}\left(s^{r}\right)$ is the same for all $s^{r}$ and $(i i)$ for some future history containing $s^{t}, \sum_{k=0}^{S} n_{k}\left(s^{k}\right) \neq \sum_{k=0}^{S} m_{k}\left(s^{k}\right)$, where $s^{t} \in s^{k}$ for all $k$. We say that the economy has a herd of investment if it has a herd for some $s^{t}$ and

$$
\sum_{k=0}^{t} n_{k}\left(s^{k}\right)=N
$$

where the summations are over $s^{k} \in s^{t}$. We say that the economy has a herd of no investment if it has a herd for some $s^{t}$ and

$$
\sum_{k=0}^{t} n_{k}\left(s^{k}\right)<N \text { and } n_{r}\left(s^{r}\right)=0 \text { for all } s^{r}, r>t \text {, and } s^{t} \in s^{r} \text {. }
$$

Note that we use the term herd to capture both the idea of a stampede, or cascade, in which investors take the same action regardless of their signal (as in Banerjee 1992 and Bikhchandani, Hirshleifer, and Welch 1992), and the idea that the actions are inefficient relative to some benchmark.

Under the following assumption, we show that the private signal economy has herds:

$$
e^{R V} Q(1)<\nu_{G}(P(1)) e^{R(V-1)} Q(2)+\nu_{B}(P(1))\left[\nu_{G}(P(0)) e^{R(V-2)} Q(1)+\nu_{B}(P(0))\right] .(13
$$


We think of (13) as a strengthened version of (8), since we know that, given (7), (13) implies (8). Assumption (13) implies that at any $t$, investing at $P(1)$ is dominated by the following strategy: Wait until $t+1$ and at that stage, if the signal is good, invest; if the signal is bad, wait until $t+2$, and then invest if and only if the signal is good.

Proposition 3. Under (6), (7), and (13), the equilibrium has both herds of investment and herds of no investment.

Proof. To see that the equilibrium has a herd of investment, consider the history of signals of length $S,(G, B, B, \ldots, B)$. In the private signal economy, $n_{0}=1$ and $n_{1}=N-1$. In the public signal economy, from (6), (7), and (13), we know that $m_{t}=0$ for all $t$. Clearly, the equilibrium also has herds of no investment. Consider the history of signals of length $S$, $(B, B, G, G, \ldots, G)$. In the private signal economy, $n_{t}=0$ for all $t$, while in the public signal economy, for $S \geq 4$ the prior rises above $P(0)$, and investment is positive. Q.E.D.

In (13), we guarantee that in the public signal economy, waiting at $P(1)$ is optimal. Suppose, instead, that we replace (13) with an assumption that guarantees that in the public signal economy, investing at $P(1)$ is optimal. Obviously, the equilibrium outcomes of the private signal economy are not affected by this change. But now the positive stampedes would not be herds, because they would coincide with the outcomes of the public signal economy.

One objection to our definition of herds is that the allocation in the public signal economy may be unattainable through an incentive scheme which respects the privacy of signals. Hence, the public signal economy may not be the right benchmark by which to gauge the efficiency of an allocation in the private signal economy. In Chari and Kehoe 
(2002), we investigate conditions under which a tax/subsidy scheme which respects the informational constraints in the private signal economy can achieve the outcome of the public signal economy. The basic idea there is that the private signal economy has an informational externality; each investor weighs the private gains and losses when making an investment decision but ignores the social gain in information that the investor's own actions provide. The tax/subsidy scheme varies only with publicly observable events, but helps align private incentives with social incentives.

\section{Macroeconomic Fundamentals vs. Herds}

We turn now to the sense in which international capital flows are driven partly by macroeconomic fundamentals and partly by herds. We show that our model is consistent with two key findings in the empirical work on financial crises. Countries with weak macroeconomic fundamentals tend to have crises more often than countries with strong macroeconomic fundamentals, and macroeconomic fundamentals alone cannot account for crises.

We think of the underlying state of the economy and the prior $\pi_{0}$ as capturing the macroeconomic fundamentals. We consider an economy with known fundamentals, what we call a fundamental economy. The differences in the outcomes in the fundamental and private signal economies result from informational frictions. (We think of the realized signals as microeconomic fundamentals which fall below the radar screen of macroeconometricians.) In the fundamental economy, capital flows are driven by fundamentals: in the good state, funds flow in with probability 1 , and in the bad state, they flow out with probability 1.

In the private signal economy, capital flows are driven partly by fundamentals and partly by herds. For a prior $\pi_{0}$ such that assumptions (6)-(8) hold, investments are of size $N$ 
after histories of the form $(1),(0,1,1), \ldots,(0,1, \ldots, 0,1,1)$. Conditional on the state being $G$, investments are of size $N$ with probability

$$
p_{G}=\alpha+(1-\alpha) \alpha^{2}+(1-\alpha)^{2} \alpha^{3}+\ldots+(1-\alpha)^{N-1} \alpha^{N}=\frac{\alpha-(1-\alpha)^{N} \alpha^{N+1}}{1-(1-\alpha) \alpha}
$$

where $\alpha$ is the probability given in (2). Conditional on the state being $B$, investments are of size $N$ with probability

$$
p_{B}=\frac{(1-\alpha)-\alpha^{N}(1-\alpha)^{N+1}}{1-(1-\alpha) \alpha} .
$$

For other histories, investments are between 0 and $S / 2$. If $N$ is large relative to $S$ and the state is good, then the distribution of capital flows is well-approximated by a binomial with realization $N$ with probability $p_{G}$ and 0 with probability $1-p_{G}$. If the state is bad, then the corresponding binomial distribution has probabilities $p_{B}$ and $1-p_{B}$.

Capital flows are related to fundamentals. Since $p_{G}>p_{B}$, capital is more likely to flow in when the state is good and more likely to flow out when the state is bad. Since both $p_{G}$ and $p_{B}$ are strictly between zero and 1, capital flows are not perfectly correlated with fundamentals. Thus, we argue that capital flows are driven partly by fundamentals and partly by herds. We summarize this discussion as follows:

Proposition 4. Capital flows are related to fundamentals in that $p_{G}>p_{B}$ and are driven partly by herds in that $0<p_{B}, p_{G}<1$.

In terms of comparing our theoretical model to the empirical literature, we imagine that the econometrician obtains many realizations of our herding outcomes - say, one for each period in the data. For each such period, the econometrician includes enough variables to pick up the macro-fundamental, namely, the state $g \in\{G, B\}$, and then computes the conditional 
probability of a financial crisis occurring. This probability is greater when fundamentals are weak. Nonetheless, even conditioning on the state, the econometrician would find a nontrivial residual (conditional) variance. If, instead, the outcomes were obtained from the fundamental economy, then the correlation between crises and fundamentals would be perfect, and the econometrician would find a zero conditional variance. This is the sense in which our model is consistent with the empirical work mentioned above.

\section{Other Regions and Nonstationary Equilibria}

So far, we have focused on what we consider to be the most interesting region of the parameter space. Now we briefly discuss the characteristics of symmetric, stationary equilibria for other regions.

If the rate of return $R$ is so low that $e^{R V} Q(1)<1$, then investors never invest regardless of the signals. If the rate of return $R$ is so high that $e^{R(V-S)} Q(-1)>1$, then all investors invest at stage 0 . If $R$ is lower than what we have, but satisfies $e^{R V} Q(0)<1$, yet $e^{R(V-S)} Q(1)>1$, then the equilibrium is very similar to the equilibrium described above. Specifically, the above equilibrium needs one good signal to set off a positive herd and two bad signals to set off a negative herd, while this one needs two good signals for a positive herd and one bad signal for a negative herd.

Next, if parameters are such that the value of waiting at $P(0)$ is less than the value of immediately investing (if the direction of the inequality is reversed in the analog of (8), where the right side is now the payoff to the optimal strategy following waiting), then all investors invest at stage 0 .

Finally, we have focused on a region of the parameter space such that, except for the 
last stage, the equilibria are stationary, in that they depend only on the prior and not on time. If we assume instead, for example, that (7) is replaced by $e^{R V} Q(-1)>1>e^{R(V-S)} Q(-1)$, then the equilibria are necessarily nonstationary and will depend on time as well as the prior.

We have also focused attention on a stationary equilibrium. Under assumptions (6)(13), the economy also has nonstationary equilibria. For example, consider the strategies we have proposed with the single change that the newly informed investor at stage 0 waits regardless of the signal. Then, at stage 1 , the beliefs of the uninformed investors stay at $P(0)$ regardless of the action of the newly informed investor at stage 0 . To show that this is an equilibrium, we need only show that the newly informed investor prefers to wait when the signal is good. By (13), waiting is optimal. It is easy to show that the qualitative characteristics of these nonstationary equilibria are the same as those of the stationary equilibrium.

\section{Endogenous Government Behavior}

So far we have worked out the behavior of the investors in our model assuming a particular set of returns for the risky investment. Now we explicitly model the source of risk as arising from default or expropriation decisions by governments.

We construct a simple maximizing model of government behavior. In our model, the government can be either competent or incompetent. Both types of government do equally well at governing during normal times, but a competent government is better than an incompetent one at dealing with difficult times. Normal times correspond to the state being good while difficult times correspond to the state being bad. Investors initially do not know the type of the government, but have prior beliefs $\pi_{0}$ that the government is competent.

After we set up this version of the model, we provide sufficient conditions for the 
competent government to never default on what it owes and for the incompetent government to default only in difficult times. Under these conditions, the return on the risky investment is given by (1), as in the model without government. We then derive two new insights from this model with government.

\section{A. The Dynamic Economy}

The dynamic economy is as follows. The economy has an infinite number of periods, each of which is divided into $V+1$ stages. The timing and information structure within each period are as before. The investors live one period and, hence, face the same problem as before. The interesting agent now is the government, which takes actions on behalf of domestic workers.

The state of the economy, $g$, follows an exogenously given i.i.d. process over normal times with probability $\mu_{G}$ and difficult times with probability $\mu_{B}\left(=1-\mu_{G}\right)$. The government must provide more services in difficult times than in normal times. We denote the level of government services in normal times by $G$ and that in difficult times by $B$. The government must finance spending on these services with a combination of taxes on investment and distorting domestic taxes. In each period, the tax rates on investment $\tau \in\{0,1\}$, so that $\tau=1$ corresponds to default. Tax revenue consists of revenue from domestic taxes $T$ plus revenue from taxes on investment $\tau x$, where the level of investment $x \in\{0,1, \ldots, N\}$.

During normal times, both types of government can govern equally well, but during difficult times, the types differ in how efficiently they can transform tax revenue $T+\tau x$ into government services. (For a related setup, see Rogoff and Sibert 1988.) Since both types

of government are equally efficient in normal times, for simplicity we normalize the level of government services that need to be provided in normal times to be $G=0$. During difficult 
times, however, both types need to provide a level of services equal to $B$. We assume that a government of type $i=C, I$ (for competent and incompetent) provides 1 unit of services for every $\theta^{i}$ unit of revenue it receives. We normalize $\theta^{C}=1$ and assume that $\theta^{I}>1 ; \theta$ is thus an incompetency parameter. In this sense, our model captures the idea that only during difficult times do the major differences between the two types of government materialize.

During difficult times, the government's budget constraint is $\theta^{i} B=T+\tau x$. During normal times, when $G=0$, tax revenue is distributed as lump-sum subsidies to workers. We capture the distortions associated with domestic taxes by letting output be a decreasing function of domestic tax revenue $T$, denoted $y(T)$ as long as $T$ is positive and $y(T)=y(0)$ otherwise. An investment of size $x$ generates extra income of $w x$ for the domestic workers, where $w$ is the labor income generated by each unit of investment. This extra income represents the benefits to the country of having investment. The consumption of domestic workers is given by $c=y(T)+w x-T$. The period utility function of the government is linear in the consumption of domestic workers. For algebraic simplicity, we assume that the government does not care about the consumption of domestic investors. From the budget constraints of the government and the workers, it follows that the period utility of government $i$ - expressed as a function of the level of government services $g$, the investment level $x$, and the default decision $\tau$-is given by

$$
U^{i}(g, x, \tau)=y\left(\theta^{i} g-\tau x\right)+w x-\left(\theta^{i} g-\tau x\right) .
$$

The government discounts future utility at rate $\beta$.

The timing of events within a period is as follows. First, the investors receive signals about the state of the economy and make investment decisions in $S$ stages as described above. 
Second, at stage $V$ the government provides some level of services, and it is publicly revealed whether times are normal or difficult. Third, the government makes its taxation and default decisions. And finally, private investors consume.

We assume that the government's default decision is publicly revealed, but that investors do not observe domestic tax revenue. (This last assumption prevents the investors from inferring the government's type in difficult times, from its budget constraint.)

For an analysis of the government's decision problem, the relevant aspect of the investors' decisions is the probability of investing conditional on the realization of $g \in\{G, B\}$ given the investors' priors $\pi$. Our equilibrium has only three relevant priors: the initial prior $\pi_{0}$ and priors of 0 and 1 . This is because in our equilibrium, either the types pool, and the prior stays at $\pi_{0}$, or they separate, and the prior moves to 0 or 1 .

We let $p_{G}(x ; \pi)$ and $p_{B}(x ; \pi)$ denote the probability of an investment of size $x$ when the prior is $\pi$ and the state is $G$ and $B$, respectively. Constructing these probabilities is easy, given the behavior of investors we have described in the previous section. For example, $p_{G}\left(N ; \pi_{0}\right)$ is given by $p_{G}$ in $(14)$, while $p_{B}\left(N ; \pi_{0}\right)$ is given by $p_{B}$ in (15). To compute, for example, $p_{G}\left(1 ; \pi_{0}\right)$ and $p_{B}\left(1 ; \pi_{0}\right)$, note that an investment of 1 unit occurs when the signal realization begins with $(B, G, B, B)$. Thus, $p_{G}\left(1 ; \pi_{0}\right)=(1-\alpha) \alpha(1-\alpha)^{2}$ and $p_{B}\left(1 ; \pi_{0}\right)=\alpha(1-\alpha) \alpha^{2}$. When $\pi=1$, it follows from the definition of $Q(k)$ that $Q(k)=1$ for all $k$, and funds of size $N$ flow in with probability 1 . Hence, $p_{G}(N ; 1)=p_{B}(N ; 1)=1$. When $\pi=0$, both types default in our equilibrium, and funds never flow in. Hence, $p_{G}(0 ; 0)=p_{B}(0 ; 0)=1$.

We focus on a Markov equilibrium in which government strategies and investor updating rules depend only on the state variables $\pi, g$, and $x$. The government takes as given 
the investing probabilities $p_{G}(x ; \pi)$ and $p_{B}(x ; \pi)$ and chooses the default decision $\tau$ to solve

$$
W^{i}(\pi, g, x)=\max _{\tau} U^{i}(g, x, \tau)+\beta \sum_{g^{\prime}=G, B} \mu_{g^{\prime}} \sum_{x^{\prime}=0}^{N} p_{g^{\prime}}\left(x^{\prime} ; \pi^{\prime}\right) W^{i}\left(\pi^{\prime}, g^{\prime}, x^{\prime}\right)
$$

where $\pi^{\prime}=\Pi(\pi, g, x, \tau)$ is the updating rule for the beliefs about the type of government and $W^{i}(\pi, g, x)$ is the value function for government $i$. Clearly, if $x=0$, there is no default decision. This dynamic programming problem gives decision rules of the form $\tau^{i}(\pi, g, x)$.

A perfect Bayesian equilibrium consists of default rules for the competent and incompetent types of government, $\tau^{C}(\cdot)$ and $\tau^{I}(\cdot)$; an updating rule $\Pi(\cdot)$ for the prior; and the probability of investing rules $p_{G}(\cdot)$ and $p_{B}(\cdot)$, such that $(i)$ given the updating and investing rules, the default rules solve the government's dynamic programming problem; (ii) the probability of investing rules are consistent with the optimality of investors' decisions given their beliefs; and ( $i i i)$ the updating rule satisfies Bayes' rule whenever possible.

We focus on an equilibrium in which the two types of government pool in normal times and separate in difficult times. More precisely, we focus on equilibria in which if $\pi=\pi_{0}$ or 1 , in normal times neither type of government defaults, while in difficult times only the incompetent type defaults. If $\pi=0$, there is no investment in equilibrium. Off the equilibrium path, if there is investing, both types default. In our construction of an equilibrium, we define strategies and updating rules only at the initial prior $\pi_{0}$, together with priors of 0 and 1 . While defining strategies and updating rules for all priors is straightforward, none of the other priors can be reached regardless of the behavior of the investors or the government.

Formally, when $x \geq 1$, the strategies are $\tau^{C}(\pi, g, x)=0$ if $\pi \in\left\{\pi_{0}, 1\right\}$ and $g \in\{G, B\}$ and $\tau^{C}(\pi, g, x)=1$ otherwise, while $\tau^{I}(\pi, g, x)=0$ if $\pi \in\left\{\pi_{0}, 1\right\}$ and $g=G$ and $\tau^{I}(\pi, g, x)=$ 1 otherwise. For $x=0$, there is no default decision. The updating rule for beliefs $\Pi(\pi, g, x, \tau)$ 
is, for $x \geq 1$,

$$
\Pi(\pi, g, x, \tau)=\left\{\begin{array}{ll}
0 & \text { if } \tau=1 \\
1 & \text { if } \tau=0 \text { and } g=B \\
\pi & \text { if } \tau=0 \text { and } g=G
\end{array}\right\}
$$

and, trivially, for $x=0, \Pi(\pi, g, 0, \tau)=\pi$, for all $g$.

Along the equilibrium path, the behavior is as follows. Starting from the initial prior and any investment $x \geq 1$, the two types of government pool by repaying in normal times, and the prior is unaffected. When difficult times come, the types separate: the competent government repays, and the incompetent government defaults. The priors move to 1 and 0 , respectively. After this separation, investors invest with probability 1 with the competent government in all future periods, and this government never defaults. Investors never again invest with the incompetent government. ${ }^{2}$

For these conjectured strategies and beliefs to constitute an equilibrium, certain inequalities must hold. We will develop these inequalities and show that they hold under the following three assumptions:

$$
y(B-N)+N-y(B) \leq \frac{\beta w N}{1-\beta} \leq y(\theta B-1)-y(\theta B)+1-\frac{\beta \mu_{B} \Delta}{1-\beta}
$$

where $\Delta=[y(\theta B-N)+N]-[y(\theta B-1)+1]$;

$$
\frac{\beta w \bar{x}}{1-\beta} \geq N
$$

\footnotetext{
${ }^{2}$ Clearly, we can extend the model to have a more complicated pattern of signaling than that considered here. By adding more government types and various states, we could have equilibria in which in less severe crises, only the most incompetent types default and hence separate, while in the more severe crises, all but the most competent types default and separate. We could also allow government types to evolve stochastically over time, say, by letting them follow a Markov process (as in Cole, Dow, and English 1995). With such a specification, after a sufficiently long period has passed after a default, lending restarts as the types drift back in expectation to the mean. Under either of these extensions, our main results would go through, and while the pattern of signaling would be richer, the algebra would become significantly more complicated.
} 
where $\bar{x}=\mu_{G} \sum_{x=0}^{N} p_{G}\left(x ; \pi_{0}\right) x+\mu_{B} \sum_{x=0}^{N} p_{B}\left(x ; \pi_{0}\right) x$ is the expected level of investment $x$ given a prior $\pi_{0}$; and

$$
\frac{\beta w}{1-\beta} \sum_{x=0}^{N} p_{B}\left(x ; \pi_{0}\right) x \geq N\left[1-p_{B}\left(0 ; \pi_{0}\right)\right] .
$$

To interpret (17), suppose that the function $y$ is concave as well as decreasing. Then, if $N$ were equal to 1 , the expression on the left side of the first inequality sign would necessarily be less than the expression on the right side of the second inequality sign. Assumption (17) is more likely to be satisfied, then, the more concave is the function $y$, the larger is the incompetency parameter $\theta$, and the smaller is $N$. Concavity of $y$ is a natural assumption and follows if the marginal deadweight cost of taxation is increasing in tax revenues, as is typically assumed. Assumption (18) requires that the present value from next period on of the average extra benefits from investment is greater than the onetime gain in reduced taxes from defaulting. Notice that both (18) and (19) are more likely to be satisfied the larger is $\beta$. We prove the following proposition in the Appendix:

Proposition 5. Under (17)-(19), the constructed strategies and beliefs constitute a perfect Bayesian equilibrium.

\section{B. Two Insights}

This model with government provides two new insights about financial crises in emerging economies.

\section{B.1. The Necessity of Difficult Times for Signaling: Tests of Fire}

Our model is predicated on the idea that difficult times provide an opportunity for a competent government to signal its competency by taking actions which are too costly for an 
incompetent government to mimic. Thus, we argue that difficult times act as tests of fire that determine the true nature of a government. But is there some other way for the government to signal its competency — say, by taking some costly action in normal times - which would work just as well? We say no, because in normal times, whatever a competent government would like to do to separate itself, an incompetent government would like to do at least as much - and can. If the competent government tried to separate itself by taking some action, then the incompetent government would mimic this action and destroy the signaling content of the action. Therefore, for a true separating test, difficult times are needed.

Consider a candidate test in normal times. Suppose an equilibrium exists in which the competent government takes a costly action during normal times to signal that it is competent. This action could be interpreted in many ways. It could be thought of, for example, as some domestic reform that is costly but might be seen as a show of good faith. For simplicity, here we simply let governments pay money to foreigners to try to signal their competency. We will show by way of contradiction that such payments could not serve as a separating signal. The potential for other costly actions, like reforms, to serve as a signal could be analyzed in a similar way.

For concreteness, suppose a signaling payment $z$ is made to some foreign entity which proves to investors that the government is competent. If this payment successfully signals the government's type, then the competent government will have an incentive to make the payment while the incompetent government will not. If that is so, then for a government starting in normal times with a prior of $\pi_{0}$, making the payment causes the prior to move to 1 , while not making it causes the prior to move to 0 . 
Proposition 6. Under (17), a government cannot make payments to signal its competency in normal times.

The idea of the proof of this proposition, given in the Appendix, is straightforward. For the two types of government, the current-period payoffs are the same. For future payoffs, however, the incompetent type values a change in the prior from 0 to 1 more than the competent type does. In the future, the competent type gains only the extra benefits of the investment project. The incompetent type could mimic the competent type and gain only these extra benefits, too, but here, as in the equilibrium without a signaling payment, the incompetent type gains more by defaulting in the bad state. Thus, whatever the competent government would pay to signal its type, the incompetent would also pay, and such payments cannot serve as a separating signal.

\section{B.2. The Cost of Bailouts: Signal-Jamming}

Our model provides another insight as well, this one about the effects on equilibrium outcomes of outside agencies bailing out governments apparently about to default on debt. We show that such bailouts in difficult times can interfere with the signaling process-bailouts jam the signals to investors about the type of government they have invested in. Thus, while bailouts may have short-term benefits, they impose long-term costs on the government being bailed out. We argue that these signal-jamming costs can arise even if a bailout is unanticipated.

To make these benefits and costs concrete, suppose that an economy is in difficult times, the state has been revealed, and the government is on the verge of defaulting on its debt. Suppose that an outside agency undertakes a onetime unanticipated bailout by making a gift of goods to the government equal to the size of the investment $x$, earmarked for repaying 
investors for their claims.

This bailout clearly has short-term benefits: with it, both types of government can reduce their distortionary taxes in difficult times by $x$. For the incompetent government, the bailout also has long-term benefits: without it, this type of government would reveal its type by defaulting, while with the bailout, it can conceal its type by not defaulting. For the competent government, however, the bailout has long-term costs: in effect, the bailout jams the competent government's signal of competency. Without the bailout, this type of government would reveal its type by repaying, while with the bailout, it is deprived of the opportunity to do that.

The competent government thus faces a trade-off between the bailout's short-term benefits of tax reduction and the bailout's long-term costs of signal-jamming. For this government, the value of utility under a bailout of size $x$ when an investment of size $x$ has been made is $y(B-x)+w x-(B-x)+\beta V^{C}\left(\pi_{0}\right)$ since the government is able to reduce its distorting taxes by $x$ but investors' priors stay at $\pi_{0}$. Here $V^{C}(\pi)$ denotes the continuation utility of a competent government with a prior of $\pi$. The utility without a bailout is $y(B)+w x-B+\beta V^{C}(1)$. Thus, the government has higher tax rates in the current period, but investors' priors move to 1 . The short-term benefits

$$
y(B-x)-y(B)+x
$$

arise because the government needs to raise less tax revenue, which has the direct effect of raising consumption by $x$, and the indirect effect of allowing the government to lower distortions and, thus, raise output. The long-term costs are $\beta\left[V^{C}(1)-V^{C}\left(\pi_{0}\right)\right]$. These costs arise because the bailout interferes with the market mechanism that allows the competent 
government to signal its type and raise its prior from $\pi_{0}$ to 1 . By jamming that signal, these bailouts lead the competent government to remain in the region with herds and volatile capital flows instead of moving to a region with no herds and smooth capital flows. Only when the next difficult times occur is the government able to signal its type. Using $t(26)$ and (30) from the Appendix, we can derive that these costs are equal to

$$
\frac{\beta w(N-\bar{x})}{1-\beta\left[1-\mu_{B} \sum_{x=1}^{N} p_{B}\left(x ; \pi_{0}\right)\right]} .
$$

In sum:

Proposition 7. Bailouts of governments have short-term benefits, but even if unanticipated, they have long-term costs.

The point of Proposition 7 is that while bailouts may well benefit both types of government, they also impose costs. In the literature, most attention has been focused on the moral hazard costs of bailouts, and these costs are now well understood. If bailouts are unanticipated, they do not lead to moral hazard. We show that even unanticipated bailouts impose another type of cost, arising from signal-jamming, one which has not received attention.

So far we have assumed that governments have no choice on whether to accept or reject a bailout. It is easy to show that if (20) is larger than (21), then both types will accept the bailout and that such an inequality is not inconsistent with our other assumptions.

\section{Conclusion}

Here we have constructed a simple model of how informational frictions in international financial markets and standard debt default problems produce herdlike capital flows with the characteristics of hot money. We have shown that our model can qualitatively account for the 
findings of Kaminsky (1999), that financial crises in emerging economies involve both weak fundamentals and a random component. Further research should assess whether a version of the model can quantitatively account for Kaminsky's findings.

For simplicity, we have assumed here that investment is a zero/one decision and that investors have no means to communicate their signals. In recent work, Chari and Kehoe (2002), we show that herds also arise in models with continuous investment and communication. 


\section{Appendix: Proofs of Propositions 5 and 6}

Proposition 5. Under (17)-(19), the constructed strategies and beliefs constitute a perfect Bayesian equilibrium.

Proof. We begin to prove Proposition 5 by analyzing the behavior of a competent government.

In difficult times, with a prior of $\pi_{0}$ or 1 and any investment level $x$, a competent government is supposed to repay its debt to investors and get a new prior of 1 rather than default and get a new prior of 0 . For that assumption to be true, the following must hold for all $x$ :

$$
y(B)+w x-B+\beta V^{C}(1) \geq y(B-x)+w x-(B-x)+\beta V^{C}(0) .
$$

That can be rearranged as

$$
\beta\left[V^{C}(1)-V^{C}(0)\right] \geq y(B-x)-y(B)+x .
$$

Here $V^{C}(1)$ and $V^{C}(0)$ are continuation payoffs to the competent government associated with priors of 1 and 0 , respectively. These continuation payoffs are the present value of expected discounted utilities from the next period on under the equilibrium strategies. We will show that for an investment of size $N$,

$$
\beta\left[V^{C}(1)-V^{C}(0)\right]=\frac{\beta w N}{1-\beta} .
$$

Then, from (17) and (24), (23) follows. In particular, we conclude that

$$
\frac{\beta w N}{1-\beta} \geq y(B-N)+N-y(B)
$$


In (25), the left side of the inequality is the discounted sum of benefits the competent government loses by having the prior move from 1 to 0 , while the right side of the inequality is the current gain the government gets by defaulting today on the investment.

To see this, note that with a prior of 1 , funds always flow in, and the competent government never defaults, so its continuation payoff is given by

$$
V^{C}(1)=\mu_{G}[y(0)+w N]+\mu_{B}[y(B)+w N-B]+\beta V^{C}(1) .
$$

With a prior of 0 , funds never flow in, and the continuation payoff is given by

$$
V^{C}(0)=\mu_{G}[y(0)]+\mu_{B}[y(B)-B]+\beta V^{C}(0) .
$$

Subtracting (27) from (??), rearranging terms, and multiplying by $\beta$ gives (24).

Now consider the competent government in normal times with a prior of $\pi_{0}$. For this government to repay at $\pi_{0}$ and continue with this prior rather than default and have a new prior of 0 , this must hold for all $x$ :

$$
y(0)+w x+\beta V^{C}\left(\pi_{0}\right) \geq y(0)+w x+x+\beta V^{C}(0)
$$

which it will if it holds for $x=N$. Thus, we need only show that

$$
\beta\left[V^{C}\left(\pi_{0}\right)-V^{C}(0)\right] \geq N .
$$

The continuation payoff $V^{C}\left(\pi_{0}\right)$ is implicitly defined by

$$
\begin{aligned}
V^{C}\left(\pi_{0}\right)= & \mu_{G} \sum_{x=0}^{N} p_{G}\left(x ; \pi_{0}\right)\left[y(0)+w x+\beta V^{C}\left(\pi_{0}\right)\right] \\
& +\mu_{B} p_{B}\left(0 ; \pi_{0}\right)\left[y(B)-B+\beta V^{C}\left(\pi_{0}\right)\right] \\
& +\mu_{B} \sum_{x=1}^{N} p_{B}\left(x ; \pi_{0}\right)\left[y(B)+w x-B+\beta V^{C}(1)\right] .
\end{aligned}
$$


To understand $(30)$, recall that with probability $\mu_{B} p_{B}\left(x ; \pi_{0}\right)$, difficult times occur, and the government receives funds of level $x$ from investors. If $x \geq 1$, then the competent government repays the investors and gets a new prior of 1 (while the incompetent government in the corresponding state defaults). In the other events, no information is revealed: The government receives the current payoff under the equilibrium strategy for that event and a continuation payoff $V^{C}\left(\pi_{0}\right)$.

To establish (29), note first that since the continuation payoffs are increasing in the prior, $V^{C}(1) \geq V^{C}\left(\pi_{0}\right)$. Using this inequality in (30) and rearranging gives

$$
V^{C}\left(\pi_{0}\right) \geq \mu_{G}[y(0)]+\mu_{B}[y(B)-B]+w \bar{x}+\beta V^{C}\left(\pi_{0}\right) .
$$

Subtracting (27) from (31) and rearranging terms gives

$$
V^{C}\left(\pi_{0}\right)-V^{C}(0) \geq \frac{w \bar{x}}{1-\beta}
$$

Together, then, (32) and (18) imply (29).

In normal times with a prior of 1 , the competent government has a similar inequality. Since the continuation payoff is increasing in the prior, this inequality is automatically satisfied whenever (29) holds.

Next we analyze the behavior of an incompetent government. In difficult times with a prior of either $\pi_{0}$ or 1 , this type of government is supposed to default on its debt and have a new prior of 0 rather than repay and have a new prior of 1 . For that assumption to be true, this must be true for all $x$ :

$$
y(\theta B-x)+w x-(\theta B-x)+\beta V^{I}(0) \geq y(\theta B)+w x-\theta B+\beta V^{I}(1) .
$$

For (33) to hold, a rearranged version of (33) must hold for $x=1$ :

$$
y(\theta B-1)-y(\theta B)+1 \geq \beta\left[V^{I}(1)-V^{I}(0)\right] .
$$


Here $V^{I}(0)$ and $V^{I}(1)$ are continuation payoffs for the incompetent government associated with priors of 0 and 1 , respectively. With a prior of 0 , funds never flow in, and the continuation payoff is given by

$$
V^{I}(0)=\mu_{G}[y(0)]+\mu_{B}[y(\theta B)-\theta B]+\beta V^{I}(0) .
$$

With a prior of 1 , funds of size $N$ flow in today. Tomorrow, under the equilibrium strategies, the incompetent government repays and keeps the prior of 1 in normal times, while it defaults and gets a new prior of 0 in difficult times. Hence, the continuation payoffs are

$$
V^{I}(1)=\mu_{G}\left[y(0)+w N+\beta V^{I}(1)\right]+\mu_{B}\left[y(\theta B-N)+w N-(\theta B-N)+\beta V^{I}(0)\right] .
$$

Subtracting (35) from (36) and rearranging terms gives

$$
V^{I}(1)-V^{I}(0)=\frac{w N+\mu_{B}[y(\theta B-N)-y(\theta B)+N]}{1-\beta \mu_{G}} .
$$

Using (37) in (34), we need only show that

$$
\left(1-\beta \mu_{G}\right)[y(\theta B-1)-y(\theta B)+1] \geq \beta\left\{w N+\mu_{B}[y(\theta B-N)-y(\theta B)+N]\right\} .
$$

Recall that we have defined $\Delta=[y(\theta B-N)+N]-[y(\theta B-1)+1]$. Using that, we can reduce (38) to

$$
y(\theta B-1)-y(\theta B)+1 \geq \frac{\beta}{1-\beta}\left[w N+\mu_{B} \Delta\right] .
$$

Hence, (34) follows from (17).

Next, in normal times, the incompetent government is supposed to repay its debt with priors of $\pi_{0}$ and 1 . Clearly, if the government repays with a prior of $\pi_{0}$, it will repay with a prior of 1 ; hence, we need only consider a prior of $\pi_{0}$. Under this prior, the government is 
supposed to repay and keep the prior $\pi_{0}$ rather than default and get a new prior of 0 . Hence, we must have that

$$
y(0)+w x+\beta V^{I}\left(\pi_{0}\right) \geq y(0)+w x+x+\beta V^{I}(0)
$$

for all $x$, which is equivalent to

$$
\beta\left[V^{I}\left(\pi_{0}\right)-V^{I}(0)\right] \geq N
$$

The continuation payoff under $\pi_{0}$ is given by

$$
\begin{aligned}
V^{I}\left(\pi_{0}\right)= & \mu_{G} \sum_{x=0}^{N} p_{G}\left(x ; \pi_{0}\right)\left[y(0)+w x+\beta V^{I}\left(\pi_{0}\right)\right] \\
& +\mu_{B} p_{B}\left(0 ; \pi_{0}\right)\left[y(B)-B+\beta V^{I}\left(\pi_{0}\right)\right] \\
& +\mu_{B} \sum_{x=1}^{N} p_{B}\left(x ; \pi_{0}\right)\left[y(\theta B-x)+w x-(\theta B-x)+\beta V^{I}(0)\right] .
\end{aligned}
$$

To understand this payoff, note that tomorrow, with probability $\mu_{B} \sum_{x=1}^{N} p_{B}\left(x ; \pi_{0}\right)$, the government receives funds in difficult times and defaults, and its prior falls to 0 . In the other events, the government does not default, no information is revealed, and the government continues with the original prior $\pi_{0}$. Subtracting $V^{I}(0)$ in (35) from $V^{I}\left(\pi_{0}\right)$ above gives

$$
\begin{aligned}
(1- & \left.\beta\left\{1-\mu_{B}\left[1-p_{B}\left(0 ; \pi_{0}\right)\right]\right\}\right)\left[V^{I}\left(\pi_{0}\right)-V^{I}(0)\right] \\
& =w \bar{x}+\mu_{B} \sum_{x=1}^{N} p_{B}\left(x ; \pi_{0}\right)[y(\theta B-x)-y(\theta B)+x] .
\end{aligned}
$$

Now the right-most inequality in (17) implies that

$$
y(\theta B-x)-y(\theta B)+x \geq \frac{\beta w x}{1-\beta}
$$


and (18) implies that

$$
w \bar{x} \geq \frac{1-\beta}{\beta} N
$$

Using (43) and (44) in (42) gives that the right side of (42) is greater than or equal to

$$
\frac{1-\beta}{\beta} N+\frac{\beta \mu_{B} w}{1-\beta} \sum_{x=1}^{N} p_{B}\left(x ; \pi_{0}\right) x .
$$

We can use this relation and (42) to imply that a sufficient condition for (41) is that

$$
\beta\left[\frac{1-\beta}{\beta} N+\frac{\beta \mu_{B} w}{1-\beta} \sum_{x=1}^{N} p_{B}\left(x ; \pi_{0}\right) x\right] \geq\left\{1-\beta\left[1-\mu_{B} \sum_{x=1}^{N} p_{B}\left(x ; \pi_{0}\right)\right]\right\} N
$$

which, with some manipulation, reduces to

$$
\frac{\beta w}{1-\beta} \geq \frac{N \sum_{x=1}^{N} p_{B}\left(x ; \pi_{0}\right)}{\sum_{x=0}^{N} p_{B}\left(x ; \pi_{0}\right) x}
$$

which is implied by (19). Q.E.D.

Proposition 6. Under (17), a government cannot make payments to signal its competency in normal times.

Proof. By way of contradiction of Proposition 6, suppose that such a signaling equilibrium exists. In particular, suppose that a payment of $z$ successfully signals the competent government's type in normal times when there has been an investment of $x$. Then the competent government must prefer to make the payment and have a prior of 1 rather than not make the payment and have a prior of 0 . Thus,

$$
y(z)+w x-z+\beta V^{C}(1) \geq y(0)+w x+\beta V^{C}(0) .
$$

Moreover, an incompetent government must prefer to not make the payment signaling competency, so that

$$
y(z)+w x-z+\beta V^{I}(1) \leq y(0)+w x+\beta V^{I}(0) .
$$


To show that (46) and (47) cannot hold, we need only show that

$$
V^{C}(1)-V^{C}(0)<V^{I}(1)-V^{I}(0)
$$

If such a signaling equilibrium existed, an incompetent government would have an incentive to deviate and actually make the payment. Using (??) and (37), we can write (48) as

$$
\frac{w N}{1-\beta}<\frac{w N+\mu_{B}[y(\theta B-N)-y(\theta B)+N]}{1-\beta \mu_{G}}
$$

which can be rearranged as

$$
\frac{\beta w N}{1-\beta}<y(\theta B-N)-y(\theta B)+N .
$$

The result then follows from (17). Q.E.D. 


\section{References}

Atkeson, Andrew, and Ríos-Rull, José-Víctor. "The Balance of Payments and Borrowing Constraints: An Alternative View of the Mexican Crisis." J. Internat. Econ. 41 (November 1996): 331-49.

Banerjee, Abhijit V. "A Simple Model of Herd Behavior. Q.J.E. 107 (August 1992): 797-817. Bikhchandani, Sushil; Hirshleifer, David; and Welch, Ivo. "A Theory of Fads, Fashion, Custom, and Cultural Change as Informational Cascades." J.P.E. 100 (October 1992): $992-1026$.

Burnside, Craig; Eichenbaum, Martin; and Rebelo, Sergio T. "On the Fundamentals of SelfFulfilling Speculative Attacks." Working Paper 7554. Cambridge, Mass.: National Bureau of Economic Research, February 2000.

Calvo, Guillermo A. "Capital Flows and Capital-Market Crises: The Simple Economics of Sudden Stops." J. Applied Econ. 1 (November 1998): 35-54.

Calvo, Guillermo A., and Mendoza, Enrique G. "Mexico's Balance-of-Payments Crisis: A Chronicle of a Death Foretold.” Manuscript. College Park, Md.: University of Maryland, Department of Economcis, 1995.

Caplin, Andrew, and Leahy, John. "Business as Usual, Market Crashes, and Wisdom After the Fact." A.E.R. 84 (June 1994): 548-65.

Chamley, Christophe, and Gale, Douglas. "Information Revelation and Strategic Delay in a Model of Investment." Econometrica 62 (September 1994): 1065-85.

Chang, Roberto, and Velasco, Andrés. "A Model of Financial Crises in Emerging Markets." Q.J.E. 116 (May 2001): 489-517. 
Chari, V. V., and Kehoe, Patrick J. "On the Robustness of Herds." Working Paper 622. Minneapolis, Minn.: Research Department, Federal Reserve Bank of Minneapolis, May 2002.

Cole, Harold L.; Dow, James; and English, William B. "Default, Settlement, and Signalling: Lending Resumption in a Reputational Model of Sovereign Debt." Internat. Econ. Rev. 36 (May 1995): 365-85.

Cole, Harold L., and Kehoe, Timothy J. "Self-Fulfilling Debt Crises." Rev. Econ. Studies 67 (January 2000): 91-116.

Eaton, Jonathan, and Fernandez, Raquel. "Sovereign Debt." In Handbook of International Economics, Vol. 3, edited by Gene M. Grossman and Kenneth Rogoff, 2031-77. Amsterdam: Elsevier, North-Holland, 1995.

Goldstein, Morris; Kaminsky, Graciela L.; and Reinhart, Carmen M. Assessing Financial Vulnerability: An Early Warning System for Emerging Markets. Washington, D.C.: Institute for International Economics, 2000.

Kaminsky, Graciela L. "Currency and Banking Crises: The Early Warnings of Distress." Working Paper 99/178. Washington, D.C.: International Monetary Fund, December 1999.

Krugman, Paul. "A Model of Balance of Payments Crises." J. Money, Credit and Banking 11 (August 1979): 311-25.

Morris, Stephen, and Shin, Hyun Song. "Rethinking Multiple Equilibria in Macroeconomic Modelling." In NBER Macroeconomics Annual 2000, Vol. 15, edited by Ben S. Bernanke and Kenneth Rogoff, 139-61. Cambridge, Mass.: MIT Press/National Bureau of Economic Research, 2001. 
Rogoff, Kenneth, and Sibert, Anne. "Elections and Macroeconomic Policy Cycles." Rev. Econ. Studies 55 (January 1988): 1-16.

Sachs, Jeffrey D.; Tornell, Aaron; and Velasco, Andrés. "The Mexican Peso Crisis: Sudden Death or Death Foretold?" J. Internat. Econ. 41 (November 1996): 265-83. 
Figure 1. Predicted Probability of a Currency Crisis in Malaysia

Semiannually, 1970-99

\section{Prob.}

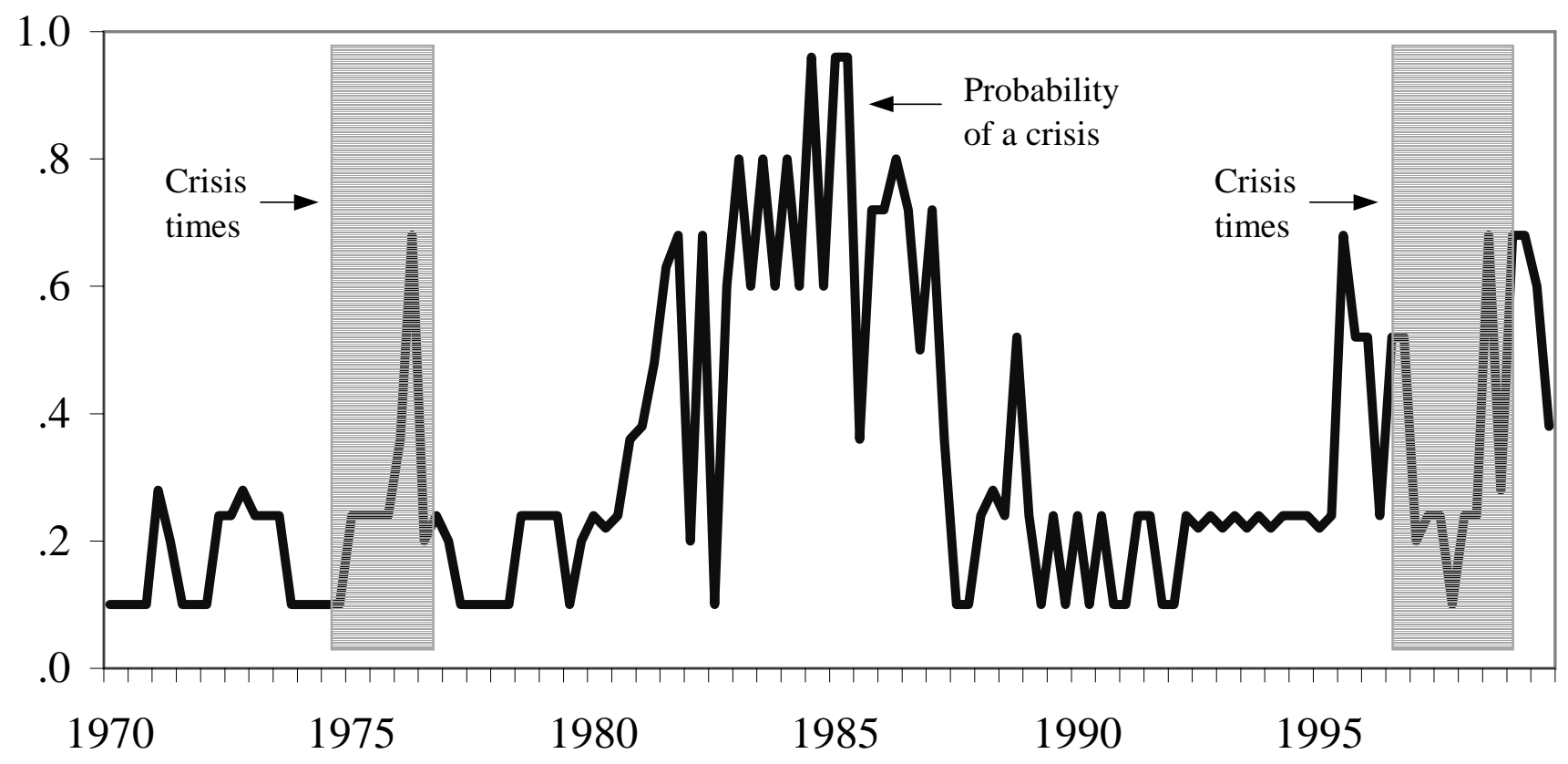

Note: Currency crises occurred in Malaysia in July 1975 and July 1997. The shaded areas indicate crises times, defined as the 24-month periods preceding the crises. All other times are tranquil times.

Source: Kaminsky (1999) 